\title{
Bilateral Carcinoma
}

National Cancer Institute

\section{Source}

National Cancer Institute. Bilateral Carcinoma. NCI Thesaurus. Code C8500.

A carcinoma that affects both sides of an organ in a simultaneous or non-simultaneous manner. 